\title{
A atuação do enfermeiro preceptor da rede básica do SUS: uma reflexão sobre suas competências
}

RESUMO I O objetivo do estudo foi refletir sobre as competências gerenciais do enfermeiro preceptor em rede básica de saúde no processo de ensino- aprendizagem. A metodologia baseou-se na reflexão do tema abordado, utilizando leis, decretos que falem sobre a formação dos enfermeiros e da preceptoria e artigos, dissertações e teses publicados entre 2014 a 2018, que discutam as competências do preceptor. A partir destas reflexões, pode-se observar o valor que tem o preceptor, seu papel na formação do discente, que não se limita somente ao preceptor, mas alcança toda a classe por ele representada sendo fortalecida por enfermeiros cada vez mais competentes. Contudo, esta reflexão, através dos trabalhos analisados, revelou a necessidade da aproximação do preceptor com a instituição de ensino a fim de reconhecer-se como coautor na relação de ensino-aprendizagem dos futuros profissionais.

Palavras-chaves: Enfermeiro; Atenção Primária à Saúde; Sistema Único de Saúde.

ABSTRACT | The aim of the study was to reflect on the managerial skills of the preceptor nurse in the basic health network in the teaching-learning process. The methodology was based on the reflection of the approached theme, using laws, decrees that speak about the formation of nurses and preceptorship and articles, dissertations and theses published between 2014 and 2018, which discuss the preceptor's competences. From these reflections, one can observe the value that the preceptor has, his role in the formation of the student, which is not limited to the preceptor, but reaches the whole class represented by him being strengthened by increasingly competent nurses. However, this reflection, through the analyzed works, revealed the necessity of approaching the preceptor with the educational institution in order to recognize himself as a co-author in the teaching-learning relationship of future professionals.

Keywords: Nurse; Primary Health Care; Unified Health System.

RESUMEN | El objetivo del estudio fue reflexionar sobre las habilidades gerenciales de la enfermera preceptora en la red básica de salud en el proceso de enseñanza-aprendizaje. La metodología se basó en la reflexión del tema abordado, utilizando leyes, decretos que hablan sobre la formación de enfermeras y preceptoría y artículos, disertaciones y tesis publicadas entre 2014 y 2018, que discuten las competencias del preceptor. A partir de estas reflexiones, se puede observar el valor que tiene el preceptor, su papel en la formación del alumno, que no se limita al preceptor, sino que llega a toda la clase representada por él fortalecido por enfermeras cada vez más competentes. Sin embargo, esta reflexión, a través de los trabajos analizados, reveló la necesidad de acercarse al preceptor con la institución educativa para reconocerse como coautor en la relación de enseñanzaaprendizaje de futuros profesionales.

Descriptores: Enfermera; Atención Primaria de Salud; Sistema Único de Salud.

\section{Rachele Breder dos Santos Rebello}

Mestranda da Universidade Federal Fluminense - UFF, Escola de Enfermagem Aurora de Afonso Costa.

\section{Geilsa Soraia Cavalcanti Valente}

Doutora em Enfermagem. Professora da Universidade Federal Fluminense UFF, Escola de Enfermagem Aurora de Afonso Costa.

Recebido em: $11 / 07 / 2019$

Aprovado em: 16/07/2019

INTRODUÇÃO

$\Lambda$ Constituição de 1988 define no Art. 196, p. que "a saúde é direito de todos e dever do Estado, garantido mediante políticas sociais e econômicas que visem à redução do risco de doença e de outros agravos e ao acesso universal e igualitário às ações e serviços para sua promoção, proteção e recuperação". Isto revela o compromisso do Estado em oferecer à população, saúde, que se dá através do estímulo à qualidade de vida, redução ou eliminação dos riscos através de medidas inespecíficas, como: vacinas, combate aos vetores, e a proteção por meio de diagnósticos, tratamentos. Apesar da Constituição abraçar as propostas do SUS, este só foi regula- mentado em 1990 com a Lei n. ${ }^{\circ} 8.080^{(1,2)}$.

Com o surgimento do Sistema Único de Saúde (SUS), houve um fortalecimento na saúde e, posteriormente, com a criação da Lei de Diretrizes e Bases da Educação Nacional - LDB $^{(3)}$, de 1996, e das Diretrizes Curriculares Nacionais - DCN/2001 ${ }^{(4)}$ do Curso de Enfermagem; os Cursos de Enfermagem passaram por um processo de reorientação, com modificações em seus currículos, trazendo para a formação as competências e habilidades dos enfermeiros para atuar no campo da Saúde.

A LDB $^{(3)}$ estabeleceu as DCN ${ }^{(4)}$ como responsáveis da Educação Superior. Estas diretrizes orientam os cursos na elaboração dos seus Projetos Político Pedagógicos (PPP), e ainda que as Instituições de 
Ensino Superior tenham liberdade para elaborar os seus PPP, devem se apoiar ao que foi definido como perfil do enfermeiro pelas DCN, as quais, em vigor desde 2001, têm sido foco de grande relevância. Nelas estão inseridos os ideais pedagógicos de Paulo Freire, formando os alunos com pensamento crítico-reflexivo, pautado em princípios éticos, capazes de conhecer e intervir sobre os problemas de saúde/doença, o professor sendo facilitador e mediador do processo ensino aprendizagem e a aprendizagem sendo o caminho que possibilita ao sujeito social transformar-se e transformar seu contexto. A aprendizagem deve ser orientada pela ação-reflexão-ação, uma estratégia didática para solucionar problemas. As DCN também determinam um novo perfil profissional baseado nos conceitos de competências para atender as novas exigências do mercado de trabalho, entendendo que, competência segundo estudo ${ }^{(5: 729)}$ : "não se efetiva apenas no âmbito dos conhecimentos e habilidades, mas demanda a mobilização destes recursos para a ação, isto é, criando condições para a aplicabilidade em situações práticas respondendo às exigências do mercado de trabalho".

Também é determinada pelas DCN, a necessidade de integração básico-profissional, ou seja, diminuição da distância entre a teoria e a prática. Para que as competências dos discentes sejam trabaIhadas, construídas durante o processo de formação, quanto mais cedo aproximá-lo da realidade, mais cedo vai "apreender" o conhecimento teórico com criticidade, vivenciando e refletindo a sua prática, tornando assim a aprendizagem significativa $^{(4)}$.

Se o aluno precisa desenvolver competências, habilidades, pensamento crítico-reflexivo, isto precisa ser estimulado pelos docentes, inclusive pelos preceptores, que também fazem parte deste processo, visto que, conforme destaca-se na Lei n. ${ }^{\circ} 8080 / 90$ Art. $27^{(2)}$, "os serviços públicos que integram o SUS constituem campo de prática para o ensino e pesqui- sa, mediante normas específicas, elaboradas conjuntamente com o sistema educacional"; entende-se que o enfermeiro, ao fazer parte do SUS, se compromete com a formação dos acadêmicos. Talvez, muitos ao entrarem no SUS não compreendam que a sua responsabilidade ultrapassa os limites do cuidado, são corresponsáveis no processo de ensino-aprendizagem dos acadêmicos. O SUS é mais do que um campo de estágio, ele é ordenador de Recursos Humanos conforme é destacado na legislação.

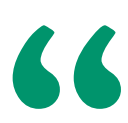

\section{A aprendizagem deve ser orientada pela ação- reflexão-ação, uma estratégia didática para solucionar problemas.}

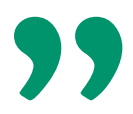

A política de recursos humanos na Área da Saúde será formalizada e executada, articuladamente pelas diferentes esferas de governo, em cumprimento dos seguintes objetivos: a organização de um sistema de formação de recursos humanos em todos os níveis de ensino, inclusive de Pós-graduação, além da elaboração de programas de permanente aperfeiçoamento de pessoal; os serviços públicos que integram o SUS constituem campo de prática para ensino e pesquisa, mediante normas específicas, elaboradas conjuntamente com o sistema educacional(2,4).
O enfermeiro atuante da rede básica do SUS é dotado de inúmeras atribuições e, mesmo sendo especialista, atua como generalista, é sobrecarregado no serviço ora por falta de recursos humanos ora por falta de recursos financeiros. Desta forma, pouco tempo Ihe resta para assumir mais uma função, orientar e acompanhar acadêmicos em campo de estágio. Alguns enfermeiros se encontram dispostos a contribuir na aprendizagem do aluno mas se veem impossibilitados por encontrar escalas de funcionários não condizentes com a demanda de serviço, falta de material, porém, o que mais acontece são enfermeiros que, por sobrecarga no serviço, "recusam" acompanhar os acadêmicos alegando não receberem mais por mais uma função. Mas a questão é: Será que os enfermeiros têm conhecimento que, uma vez inseridos no SUS também fazem parte do processo de formação dos acadêmicos? Será que os enfermeiros conhecem a Lei Orgânica, que regulamenta o Sistema de Saúde, Lei n. ${ }^{\circ}$ 8080/90(2)? Será que os enfermeiros preceptores têm competências para atuar no processo de ensino-aprendizagem com os acadêmicos de enfermagem?

Importante ratificar que, o contrário de competência não é incompetência. $\mathrm{O}$ fato de o enfermeiro não possuir competência para atuar neste processo quer dizer que ele não detém os atributos necessários para se responsabilizar no processo ensino-aprendizagem com os alunos como habilidade, atitude, conhecimento, porém, é competente no exercício da sua profissão. Se lutamos por um sistema de saúde mais justo, capaz de atingir os princípios doutrinários do SUS, precisamos formar profissionais que militem com competência e habilidade, mas para que este ideal seja atingido, é preciso que os profissionais sirvam de exemplo para aqueles que estão se inserindo no campo de trabalho, quer seja através de visita técnica, estágio curricular, extracurricular ou por atuar profissionalmente.

Cabe ao enfermeiro, sobretudo na docência, na preceptoria, compartilhar 
conhecimentos; facilitar o processo de aprendizagem utilizando as habilidades desenvolvidas em sua formação, ações educativas, planejamento, criatividade, motivação e interagir com as IES e com os integrantes da equipe de saúde, a fim de atingir as metas inerentes ao processo de ensino e de aprendizagem. Para isto, faz-se necessário adquirir e desenvolver competências continuamente.

A origem do termo preceptor vem do latim paraecipio, que significa "mandar com império aos que lhe são inferiores $^{\prime \prime(6: 365)}$. Estudo ${ }^{(7: 43)}$ cita que, para estes autores, a terminologia preceptor é utilizada para designar o profissional que atua dentro do espaço de trabalho e de formação, estritamente na área e no momento da prática clínica, que ensina a clinicar em situações reais no próprio ambiente de trabalho e participa da avaliação dos alunos. O preceptor deve ter conhecimento e habilidade em desempenhar procedimentos clínicos, preocupando-se também com aspectos de ensino-aprendizagem.

Para autores ${ }^{(8)}$, preceptoria é a situação de aprendizado na qual o conhecimento e a habilidade são geradas através da participação do processo de cuidado de pacientes na prática clínica. Sendo um método para garantir desenvolvimento profissional contínuo e entrega segura, ética e eficaz do cuidado. A preceptoria tem sido amplamente documentada para facilitar efetivamente o aprendizado em clínica configurações e, portanto, desenvolvimento de independência e competência dos enfermeiros.

Este artigo é um recorte da Dissertação de Mestrado Profissional em Ensino na Saúde, tendo como foco educação permanente no serviço como estratégia para o desenvolvimento das competências gerais e gerenciais do enfermeiro preceptor de estágio na Atenção Básica de Saúde. Dessa forma, busca-se, através das competências gerenciais do enfermeiro preceptor da rede básica do SUS, refletir se ele se vê como protagonista no processo de ensino-aprendizagem do acadêmico de enfermagem. Durante a elaboração do estudo, foi possível reconhecer a importância do processo de ensino-aprendizagem nos discentes de enfermagem e perceber a importante contribuição dos enfermeiros preceptores no cumprimento deste papel, tendo em vista que as IES devem formar o aluno com vistas ao SUS, porque uma das orientações das DCN é formar enfermeiro generalista capaz de atender a demanda da atenção básica. Logo, percebe-se a importância da articulação do serviço de saúde com a IE. Portanto, este trabalho tem objetivo de refletir sobre as competências gerenciais do enfermeiro preceptor em rede básica de saúde no processo de ensino-aprendizagem.

\section{METODOLOGIA}

Trata-se de um estudo descritivo baseado na reflexão do tema abordado, utilizando para auxiliar nesta reflexão, leis, decretos que falem sobre a formação dos enfermeiros e a preceptoria e artigos, dissertações e teses publicados entre 2014 a 2018, que discutam as competências do preceptor. Como referencial teórico deste estudo, elegeu-se Phillipe Perrenoud, sociólogo, professor de ensino e pesquisa na Faculdade de Psicologia e de Ciências da Educação da Universidade de Genebra. Perrenoud contribui com seus conceitos sobre saberes e competências profissionais ${ }^{(7)}$.

A fim de realizar o estado da arte sobre a temática, foi realizado um levantamento de dados, utilizando o portal da Biblioteca Virtual em Saúde (BVS), nas bases Literatura Latino-Americana e do Caribe em Ciências da Saúde (LILACS) e Base de Dados de Enfermagem (BDENF) e, no portal da PubMed, na base United States National Library of Medicine (Medline) no período de agosto a setembro de 2018. Para traçar os descritores, foi levantado um questionamento: De que maneira a educação permanente, sendo uma competência gerencial do enfermeiro, pode contribuir para o desenvolvimento da preceptoria no processo de ensino-aprendizagem? Mediante esta pergunta, foram elaborados os seguintes descritores: 1) "enfermeiras de saúde pública"; 2) "preceptoria"; 3 ) "competência profissional"; e 4) "educação continuada". Foi realizado um levantamento de material científico por descritores individualmente, em dupla e em trio. Os critérios de inclusão para a seleção foram trabalhos publicados disponíveis de 2014 a 2018 nos idiomas inglês e português e textos completos.

\section{RESULTADO E DISCUSSÃO}

Atuação do enfermeiro preceptor no processo de ensino-aprendizagem do discente na rede básica do SUS

O marco da história das Políticas Públicas no Brasil iniciou com o Movimento da Reforma Sanitária que mobilizou estudantes, profissionais, intelectuais, a população de forma geral, todavia, o conceito ampliado de saúde foi discutido na VIII Conferência Nacional de Saúde e, efetivamente constituído com a homologação da Constituição Federal de 1988 que assegurou, segundo estudo ${ }^{(9)}$, diversas garantias dos direitos fundamentais como destaca nos Artigos 196 e 200 da Constituição referentes à saúde pública e, finalmente, com a aprovação e criação do SUS com a Lei n. ${ }^{\circ}$ 8080/90 também conhecida como Lei Orgânica(2).

No ano de 1986, o MS convocou técnicos, gestores de saúde e usuários para uma discussão aberta sobre a reforma do sistema de saúde, realizando, assim, a VIII Conferência Nacional de Saúde (VIII CNS), tal qual foi um marco histórico da política de saúde brasileira, pois, pela primeira vez contava-se com a participação da comunidade e dos técnicos na discussão de uma política setorial. A Conferência reuniu cerca de 4.000 pessoas nos debates e aprovou, por unanimidade, a diretriz da universalização da saúde e o controle social efetivo com relação às práticas de saúde estabelecidas ${ }^{(10)}$.

Mesmo com toda esta conquista no 
campo das Políticas Públicas de Saúde, ainda se fazia necessária mudança na formação do profissional, sobretudo, no profissional da saúde. Surge então, em 1996, a proposta de reformulação da LDB de 1961 estabelecendo as DCN como responsáveis pela educação superior. Conforme destaca o Parecer do CNE n. ${ }^{\circ} 776 / 97$, que estabelece orientações gerais a serem observadas na formulação das DCN para os Cursos de Graduação, os quais precisam ser conduzidos através das Diretrizes Curriculares a abandonar as características de que muitas vezes se revestem, quais sejam as de atuare como meros instrumentos de transmissão de conhecimento e informações, passando a orientar-se para oferecer uma sólida formação básica, preparando o futuro graduado para enfrentar os desafios das rápidas transformações da sociedade, do mercado de trabalho e das condições de exercício profissional $^{(3)}$.

O Parecer n. ${ }^{\circ} 1.133 / 2001$, que institui as DCN do Curso de Graduação em Enfermagem, destaca no Art $6^{\circ}, \S 2^{\circ}$ parágrafo, o conjunto de competências, conteúdos e habilidades que devem promover no aluno e no enfermeiro a capacidade de desenvolvimento intelectual e profissional autônomo e permanente. Entende-se que a competência preconizada pela DCN do Curso de Enfermagem refere-se ao cuidado nas dimensões ética, política, social e na relação interpessoal. ${ }^{(4)} \mathrm{A}$ LDB $^{(3)}$, de 1996, estabeleceu DCN como responsáveis da Educação e, especialmente na Graduação em Enfermagem, determinando um novo perfil profissional baseado nos conceitos de competências para atender às novas exigências do mercado de trabalho, estando ele cada vez mais complexo.

O Art. $4^{\circ}$ determina que a formação do enfermeiro tem por objetivo dotar o profissional dos conhecimentos requeridos para o exercício das seguintes competências e habilidades gerais:

I - Atenção à saúde: os profissionais de saúde, dentro de seu âmbito profissional, devem estar aptos a desenvolver ações de prevenção, promoção, proteção e reabilitação da saúde, tanto em nível individual quanto coletivo. Cada profissional deve assegurar que sua prática seja realizada de forma integrada e contínua com as demais instâncias do sistema de saúde, sendo capaz de pensar criticamente, de analisar os problemas da sociedade e de procurar soluções para os mesmos. Os profissionais devem realizar seus serviços dentro dos mais altos padrões de qualidade e dos princípios da ética/bioética, tendo em conta que a responsabilidade da atenção à saúde não se encerra com o ato técnico, mas sim, com a resolução do problema de saúde, tanto em nível individual como coletivo;

II - Tomada de decisões: o trabalho dos profissionais de saúde deve estar fundamentado na capacidade de tomar decisões visando o uso apropriado, eficácia e custo-efetividade, da força de trabalho, de medicamentos, de equipamentos, de procedimentos e de práticas. Para este fim, os mesmos devem possuir competências e habilidades para avaliar, sistematizar e decidir as condutas mais adequadas, baseadas em evidências científicas;

III - Comunicação: os profissionais de saúde devem ser acessíveis e devem manter a confidencialidade das informações a eles confiadas, na interação com outros profissionais de saúde e o público em geral. A comunicação envolve comunicação verbal, não-verbal e habilidades de escrita e leitura; o domínio de, pelo menos, uma língua estrangeira e de tecnologias de comunicação e informação;

IV - Liderança: no trabalho em equipe multiprofissional, os profissionais de saúde deverão estar aptos a assumir posições de liderança, sempre tendo em vista o bem-estar da comunidade. A liderança envolve compromisso, responsabilidade, empatia, habilidade para tomada de decisões, comunicação e gerenciamento de forma efetiva e eficaz;

$V$ - Administração e gerenciamento: os profissionais devem estar aptos a tomar iniciativas, fazer o gerenciamento e administração tanto da força de trabalho quanto dos recursos físicos, materiais e de informação, da mesma forma que devem estar aptos a serem empreendedores, gestores, empregadores ou lideranças na equipe de saúde;

VI - Educação permanente: os profissionais devem ser capazes de aprender continuamente, tanto na sua formação, quanto na sua prática. Desta forma, os profissionais de saúde devem aprender a aprender e ter responsabilidade e compromisso com a sua educação e o(s) treinamento/estágios das futuras gerações de profissionais, mas proporcionando condições para que haja benefício mútuo entre os futuros profissionais e os profissionais dos serviços, inclusive, estimulando e desenvolvendo a mobilidade acadêmico-profissional, a formação e a cooperação por meio de redes nacionais e internacionais ${ }^{(4)}$.

Não há tempo hábil para esperar o aluno se formar e a partir daí buscar as devidas competências e habilidades a fim de suprir as necessidades do mercado de trabalho. As IES devem assumir o compromisso com os discentes: transmitir o conhecimento teórico inserindo-os e contextualizando-os de forma crítica e reflexiva, com ética e responsabilidade no campo prático; desmistificar o conceito de desarticulação entre o ensino e o serviço aproximando os profissionais da saúde, que se encontram nos campos de estágios, ao processo de ensino. Segundo estudo $^{(8)}$, as mudanças nos sistemas de saúde estão em andamento, levando a uma necessidade de novas competências entre os profissionais de saúde.

Os Ministérios da Saúde e da Educação (MS/MEC) precisam estar articulados, mas ao refletirmos sobre este tema, percebe-se a desarticulação das IES com as unidades de saúde que compõem o SUS, ou seja, a desarticulação entre teoria e prática. O SUS tem participação na formação dos profissionais da saúde e os projetos políticos pedagógicos (PPP) dos Cursos de Enfermagem devem vir de encontro às práticas de saúde. O Projeto Pedagógico, segundo o Parecer n. ${ }^{\circ}$ 1.133/2001 no Art $9^{\circ}$, deverá buscar a formação integral e 
adequada do estudante através de uma articulação entre o ensino, a pesquisa e a extensão/assistência. Assim, segundo estudo $^{(10: 16)}$, a parceria entre o ensino e o serviço resulta um processo articulador que facilita o trabalho entre educação e saúde, e que, também procura "vencer a permanente dicotomia entre pensar e fazer, entre geral e específico, integrando ações e habilidades teóricas e práticas".

Estudo $^{(11)}$ traz a discussão sobre a importância da integração entre o serviço de saúde na atenção básica e a IE, entendendo que, se esta levar o aluno a desenvolver um pensamento crítico reflexivo, trará benefício a ele como profissional, pois saberá enfrentar os problemas advindos do serviço; caso contrário, se a IE não cumprir esse papel, os alunos, futuros profissionais, terão dificuldade em alcançar os objetivos da PNEPS, uma aprendizagem no trabalho a fim de produzir mudanças nas práticas por meio da problematização gerando aproximação do serviço com os profissionais e usuários.

Outro estudo $^{(12)}$ diz que a proposta da EPS trouxe grande entusiasmo para quem sonha com uma educação transformadora na saúde. Ele continua em seu artigo discutindo que, a transformação do trabalho do SUS é ancorada na EPS a partir de três fundamentos centrais: micropolítico do trabalho vivo, método da roda e problematização/aprendizagem. Dentre estes, vale destacar que o método da roda é baseado na possibilidade dos atores (profissionais, docentes, discentes e usuários) expressarem seus desejos, opiniões, interesses com liberdade e subjetividade, eliminando as diferenças e a hierarquia entre os componentes do quadrilátero: ensino, gestão, atenção e controle social.

Alcançar a PNEPS na sua plenitude significa buscar mudança no processo de educação. Embora esta se faça presente em todas as circunstâncias da vida; ao se referir à formação profissional, observa-se a necessidade de se aplicar uma prática pedagógica com metodologia inovadora pertinente àquilo que a PNEPS propõe. Caso, as IES mantenham uma prática tradicional, engessada, não inserindo o discente neste processo evolutivo, conhecendo as demandas do setor saúde, o próprio poderá apresentar dificuldade ao chegar no campo de estágio levando uma bagagem de inseguranças e incertezas para a sua vida profissional.

Após análise de alguns autores ${ }^{(11)}$ para identificar um caminho da formação em saúde, a fim de refletir sobre a pedagogia da educação em saúde, destacam a figura do preceptor, que tem como função ensinar a clinicar através de instruções formais e com objetivos e metas claramente definidos.

Cabe ao enfermeiro, sobretudo na preceptoria, compartilhar conhecimentos; facilitar o processo de aprendizagem utilizando as habilidades desenvolvidas em sua formação, ações educativas, planejamento, criatividade, motivação e interagir com as Instituições de Ensino Superior e com os integrantes da equipe de saúde, a fim de atingir as metas inerentes ao processo de ensino e de aprendizagem. Para isso, faz-se necessário adquirir e desenvolver competências continuamente.

Os desafios da articulação entre educação e serviço de saúde

A articulação entre o ensino e o serviço ocorreu, a nível federal, com a implantação de alguns programas, dentre eles o Programa Nacional de Reorientação da Formação Profissional em Saúde (Pró-Saúde) e o Programa de Educação pelo Trabalho para a Saúde (PET-Saúde). Estudo $^{(13)}$ destaca que, a implementação do Pró-Saúde trouxe mais diálogo, aproximação entre o ensino e o serviço e diminuição das diferenças antes existentes entre eles. Embora as expectativas entre o ensino e o serviço estejam se aproximando, ainda assim nota-se um grande desafio na integração da IE com o serviço.

Estudo $^{(13)}$ cita que as expectativas dos docentes em relação ao serviço giram em torno de requisitos para aprendizagem do aluno (profissionais acessíveis que permitam a integração com a equipe local, que ofereçam condições favo- ráveis ao ensino e ao acolhimento pela equipe. No entanto, para os enfermeiros assistenciais existe uma dicotomia entre campo de estágio para campo de trabaIho e muito destes enfermeiros esperam que os estudantes devam suprir a falta de profissionais. Ratifica-se a afirmação dizendo que para as IE, os serviços de saúde são apenas campo de estágio e, para o serviço, os estudantes são considerados mão de obra. O enfermeiro, ao exercer a preceptoria, com o olhar voltado exclusivamente para a técnica, negligenciando a teoria e a didática, não vai contribuir efetivamente com o aluno na condução de uma aprendizagem significativa, vai intensificar as dificuldades e os desafios desvinculando a prática da teoria, caminhando na direção contrária à proposta da integração entre o ensino e o serviço.

Outra dificuldade encontrada na articulação entre a IE e o serviço pode ser observada nas admissões de enfermeiros recém-formados, inexperientes, despreparados para exercer a função de preceptor ou assistencial e, admissões temporárias dos trabalhadores no serviço de saúde através de contratos gerando constantes rodízios no quadro de profissionais. Estas dificuldades causam descontinuidade no processo de trabalho afetando os discentes, que terão dificuldade de encontrar um ambiente acolhedor e com profissionais habilitados no acompanhamento de preceptoria. "Quando ocorrem substituições dos agentes envolvidos, as incertezas do início da relação retornam, os níveis de informalidade e confiança, que já existiam, são quebrados, e a parceria caminha para a dissolução ou exige um novo ciclo de negociação, estabelecimento de compromisso para possibilitar a execução" ${ }^{\prime \prime(13: 542)}$.

Estudo $^{(14)}$ cita que, no Japão, tem havido pressão sobre os profissionais de saúde pública, pois devem estar preparados para uma saúde pública emergencial devido às frequentes ocorrências de desastres naturais. Por isso, os enfermeiros são obrigados a completar os currículos a fim de obter licença específica para ser enfermeiro de 
saúde pública. Porém, observa-se que a competência profissional dos enfermeiros de saúde pública recém-formados é menor do que os requisitos mínimos definidos pelo Ministério da Saúde. Dentre os fatores atribuídos a isto, destaca-se a falta de preparação de enfermeiros de saúde pública que ensinam e supervisionam os alunos no ambiente clínico.

O desconhecimento que muitos enfermeiros preceptores têm do PPP da IE e a falta de comunicação deles com a IES também podem ser caracterizadas como uma dificuldade. Isto gera um obstáculo na compreensão do grau de entendimento dos alunos. O processo avaliativo dos discentes também determina um desafio na integração. Mesmo que haja um supervisor de estágio caracterizado como professor da IES, ele não dá conta de acompanhar e avaliar os alunos, que estão distribuídos na unidade de saúde, portanto, compete ao preceptor exercer esta função, mas para isso precisa do apoio da IES na transmissão e treinamento do material avaliativo aos preceptores.

O grande problema é que, com o sucateamento da saúde pública, profissionais não conseguem alcançar a importância que têm no processo de educação, visto que enfrentam inúmeros desafios quanto à falta de insumos, mão de obra, demanda cada vez maior do usuário. Isto tudo gera conflito no trabalho, pois a IES insere seus discentes e docentes através de uma formalização entre a IES e a Secretaria Municipal de Saúde com apresentação de documentos da IE e dos alunos. Por meio desta relação de contrato, ocorre a autorização da permanência da IE na UBS. Portanto, com este aval e a obrigatoriedade do SUS em assistir aos alunos, através da Lei n. ${ }^{\circ} 8.080$ Art. 27, a ação de preceptoria não surge como um favor. Os alunos precisam praticar e do apoio dos profissionais das unidades e o docente precisa estar unido, alinhado a estes profissionais sentindo-se acolhido, seguro na certeza de que seus alunos estão recebendo uma boa instrução. Todos estes problemas elencados estão atrelados a um problema primário, capaz de gerar consequências negativas aos discentes.

\section{CONCLUSÃO}

O estágio supervisionado é a etapa do curso mais esperada na vida do acadêmico, é o momento em que todo o conteúdo teórico apreendido será, finalmente, aplicado. O preceptor, sendo o enfermeiro assistencial, precisa internalizar que, mesmo atuando no serviço básico de saúde, deve agir como protagonista no processo de ensino-aprendizagem, tendo em vista ser uma das normas do SUS, todavia, nota-se uma desarticulação da IE com o serviço de saúde. Foram observadas características capazes de potencializar esta desarticulação: falta de acolhimento do docente e discente pelo preceptor no campo de estágio quer seja pelo rodízio de profissionais ou pela inexperiência e despreparo para exercer o papel de preceptoria; um olhar de preceptor voltado, exclusivamente para a técnica; atribuir ao discente a obrigatoriedade do cumprimento do serviço como mão de obra.

O enfermeiro assistencial, ao exercer a preceptoria, precisa semear na vida do discente, futuro profissional, a valorização, o respeito à profissão, o conhecimento da rotina do serviço, a preocupação e a responsabilidade com o usuário e o conhecimento das necessidades que abrangem o SUS.

A partir destas reflexões, pode-se observar o valor que tem o preceptor, seu papel na formação do discente, que não se limita somente ao preceptor, mas alcança toda a classe por ele representada, sendo fortalecida por enfermeiros cada vez mais competentes. Contudo, esta reflexão, através dos trabalhos analisados, revelou-se a necessidade da aproximação do preceptor com a IE a fim de reconhecer-se como coautor na relação de ensino-aprendizagem dos futuros profissionais.

\section{Referências}

1. Brasil. Constituição (1988). Constituição da República Federativa do Brasil. Brasília, DF: Senado Federal: Centro Gráfico, 1988.

2. Brasil. Lei n. ${ }^{\circ} 8.080$, de 19 de setembro de 1990.

3. Ministério da Educação, Conselho Nacional de Educação (BR). Parecer n. ${ }^{\circ}$ $776 / 97$ do Conselho Nacional de Educação. Orienta para as Diretrizes Curriculares dos Cursos de Graduação, 1997.

4. Ministério da Educação, Conselho Nacional de Educação (BR). Diretrizes Curriculares Nacionais dos Cursos de Graduação em Enfermagem, Medicina e Nutrição. CNE/CES, 2001.

5. Manenti AS, et al. 0 processo de construção do perfil de competências gerenciais para enfermeiros coordenadores de área hospitalar. Rev. Esc. Enferm USP. 2012; 46(3):727-33.

6. Botti SH, Rego S. Preceptor, Supervisor, Tutor e Mentor: Quais são seus papéis? Revista Brasileira de Educação Médica. 2008; 32(3):363-373.

7. Ferreira FC. Os saberes e competências do enfermeiro para a preceptoria de graduandos em unidade básica de saúde: implicações na sua formação permanente. Dissertação (Mestrado Profissional em Ensino na Saúde) - Universidade Federal Fluminense, 2014.
8. Nielsen $\mathrm{K}$, et al. The art of preceptorship: a qualitative study. Nurse Education in Practice. 2017; (26):39-45.

9. Neves M. (Não) solucionando problemas constitucionais: transconstitucionalismo além de colisões. Lua Nova. 2014; 93: 201-232.

10. Cezario JEPlatner. 0 desafio da articulação entre a formação em saúde e a integração ensino-serviço. (Mestrado Profissional em Ensino na Saúde) - Universidade Federal Fluminense, 2013.

11. Neta AA, Alves MSCF. A comunidade como local de protagonismo na integração ensino-serviço e atuação multiprofissional. Trab. Educ. Saúde. 2016; 14(1):221-235.

12. Lemos CLS. Educação permanente em saúde no Brasil: educação ou gerenciamento permanente? Ciência \& Saúde Coletiva. 2016; 21(3):913-922.

13. Andrade SR, et al. Percepções de enfermeiros docentes e assistenciais sobre a parceria ensino-serviço em unidades de saúde. Interface, comunicação, saúde, educação. 2015; 19 (54): 537-47.

14. Kotera S, Matsuda N. The role performance of public health nurses as clinical instructors in Japan. International Council of Nurses, 2014. 